\title{
Nitrogenoa: iragana eta orainaldia konektaturik
}

\author{
Astrid Barona Fernandez, Begoña Etxebarria Robledo, Estibaliz Díaz Tena, \\ Naiara Rojo Azaceta, Gorka Gallastegui Ruiz de Gordoa \\ Euskal Herriko Unibertsitatea UPV/EHU
}

\begin{abstract}
Airearen osagai nagusia den nitrogeno gasak lotura historiko estua du gizartearen garapen ekonomiko, sozial eta politikoarekin, amoniakoaren sintesian izan duen protagonismoa dela-eta. 1908. urtean Fritz Haber-ek lorturiko amoniakoaren sintesia kimikaren mugarri zientifikoa izan zen, eta, aldi berean, aurkako helburuak zituzten sektore industrial askoren garapena goitik behera aldatu zuen aurkikuntza horrek, hala nola biztanleriaren hazkundea bermatzen zuten laborantza-ongarrien ekoizpena eta gerra-xederako fabrikatzen ziren lehergaien industria erabat transformatu zituen. Egia esan, XX. mendearen hasierako hamarkadetako arazoak konpontzeko aurrerapen itzela izan zen, eta oraindik ere sintesi-prozesu horren menpe bizi gara. Ez du ordezkorik, baina kontuan izan behar dugu haren inpaktu ekologikoa jasanezina dela eta gaur egun ingurumenarekiko kalteak agerian daudela. Beraz, historian zehar amoniakoaren sintesiaren berrikuntza historikoak gizateriaren alde eta kontra eragin dituen ondorioak eta kontraesanak erakustea da artikulu honen helburua.
\end{abstract}

GAKO-HITZAK: Nitrogenoa · Ongarriak · Iraunkortasuna · Haber.

\section{Nitrogen: connecting past with present}

Gaseous nitrogen - the major component of air - has played a decisive role in humanity's economic, social and political development, as it is crucial for the synthesis of ammonia. In 1908, the chemist Fritz Haber became the first person to synthesize ammonia in a laboratory, marking a new milestone in chemistry. This achievement led to a revolution in productive activities with fully opposite uses. For example, the process allowed manufacturing fertilizers, which clearly had a knock-on effect on food production, and therefore population growth. By contrast, the manufacture of explosives for military purposes also underwent a radical change. Nevertheless, although the fixation of atmospheric nitrogen was the solution for many problems in the early 20th century, it is remarkable that the world's population still depends on it. No feasible, sustainable replacement has been found, and its environmental ramifications will have to be addressed sooner rather than later. The objective of this article is to highlight the contradictions and the pros and cons that arose from the ammonia synthesis along history.

KEY WORDS: Nitrogen · Fertilizers · Sustainability · Haber. 


\section{Sarrera}

Nitrogenoa taula periodikoan aurki daitekeen elementurik paradoxikoenetariko bat da. Nitrogenoz osaturiko atmosfera geldoan sugarrak itzali eta animaliak hil egiten dira, baina aldi berean, lehen mailako bioelementu gisa sailkatu ohi da, karbono, hidrogeno eta oxigenoarekin batera.

Nitrogenoaren erreserba nagusia atmosfera da; izan ere, atmosfera osatzen duten gas guztien artean, nitrogenoa \% 78 da (bolumenez). Hala eta guztiz ere, izaki bizidun gehienok ezin dugu atmosferan dagoen nitrogeno molekularra $\left(\mathrm{N}_{2}\right)$ erabili aminoazidoak edo beste nitrogenodun konposatuak sintetizatzeko, eta beraz, lurzoruan aurkitzen diren gatz mineralen nitrogeno-iturriaren menpe gaude (Hager, 2008).

Biosferan ugaria izan arren, lurzoruan dagoen nitrogeno erabilgarriaren gabezia da landareen hazkundea mugatzen duen eragile nagusietariko bat. Lurzoruen emankortasun errentagarria ziurtatzeko nahitaezkoa izan da beti nitrogenodun ongarriak erabiltzea eta gaur egun ere derrigorrezkoa da laborantza-jardueretan.

Ongarrietan ez ezik, meatzaritzan, eraikuntzan, industrian zein gatazka militarretan sarri erabiltzen diren zenbait konposatu oso erreakzionakorretan ere agertzen da nitrogenoa, hala nola nitrogeno triioduro $\left(\mathrm{NI}_{3}\right)$, nitroglizerina $\left(\mathrm{C}_{3} \mathrm{H}_{5} \mathrm{~N}_{3} \mathrm{O}_{9}\right)$ edo trinitrotoluenoan $\left(\mathrm{C}_{7} \mathrm{H}_{5} \mathrm{~N}_{3} \mathrm{O}_{6}\right)$.

Duela 120 urte arte, konposatu nitrogenodunak ekoizteko iturriak nahiko eskasak ziren. Nitrogeno atmosferikoa finkatzeko eta erabili ahal izateko bideren bat aurkitzea ezinbestekoa bihurtu zen, eta hori erdiestea nahitaezkoa zirudien arren, erronka zientifiko itzela izan zen $\mathrm{N}_{2}$ molekularen nitrogeno-atomo bien arteko lotura hirukoitz kobalentearen egonkortasuna dela-eta. Helburua 1908an jadetsi zen, Fritz Haber kimikari alemaniarrak amoniakoa $\left(\mathrm{NH}_{3}\right)$ sintetizatzea lortu zuenean. Konposatu hori, ongarrien fabrikaziorako ezinbestekoa izateaz gain, lehergaien osagai nagusietariko bat den azido nitrikoa lortzeko ere baliagarria da.

Alde batetik, ongarri nitrogenodunen erabilera nekazaritza-arloan aurrerapauso ukaezintzat jo da hazkunde etengabean dagoen giza biztanleriaren gosea asetzeko; bestetik, ageriko eragin negatiboa sortu du ingurumenean, ur-ekosistemen eutrofizazioa eta atmosferaren desoreka ekarri dituelako, besteak beste. Garai bateko garrantzi handiko arazoei aurre egiteko balio izan bazuen ere, iraunkortasunaren oinarrizko printzipioei uko egitea ere ekarri du (Barona et al, 2017).

Beraz, historian zehar amoniakoaren sintesiaren berrikuntza historikoak gizateriaren alde eta kontra eragin dituen ondorioak eta kontraesanak erakustea da artikulu honen helburua. Jarraituriko metodologia zati bitan banatu da: alde batetik azterketa bibliografiko sakona egin da berrikuntzaren sormena eta eboluzioa aztertzeko, eta, bestetik, aurkituriko argibidea ordenatu egin da, ehun urte dituen berrikuntza horren onurak eta kalteak gaur egun arte heltzen direla azpimarratzeko. 


\section{Nitrogenoa ongarrien historian}

XVIII. mendetik aurrera ohiko nekazaritzaren gainbeheraren seinale larriak azaldu ziren, gehiegizko ustiapenak lurzoruaren emankortasun naturala agortzea eragin baitzuen. Nekazaritzak, ordura arte ezagutzen ziren ekoizpen-teknika bakunak erabiliz, ezin zuen ase biztanleriaren etengabeko hazkuntzaren premia, are eta gutxiago hiri handietan kontzentratuta bizi zen biztanleriaren beharrak bete.

Thomas Malthus britainiarrak, 1798an, honakoa idatzi zuen: «Biztanleria, beste baldintzatzailerik ez badago, arrazoi geometrikoan hazten da; elikagaien ekoizpena, aldiz, arrazoi aritmetikoan» (Malthus eta Keynes, 2016). Argi ikusten da lehenengo faktorea indartsuagoa dela bigarrena baino. 1898an, William Ramsayk (airean dauden gas geldoen aurkikuntzagatik 1904an Kimikako Nobel saria irabazi zuenak) ideia berdina azpimarratu zuen. Mundu mailan «nitrogeno finkoa» agortzen ari zela adierazi eta $X X$. mendearen erdialdean elikagaien urritasuna gertatuko zela aurresan zuen. XX. mendearen hasieran elikagaien produkzioa handitzearen beharra nabaria zen, munduko biztanleriaren hazkuntza azkarrari aurre egiteko. Hori dela-eta, garai hartako zientzialariek saiakuntza-ahalegin handiak egin zituzten ongarri sintetiko merkeak lortzeko. Zientzialariek bazekiten nitrogenoa landareen oinarrizko mantenugaia zela, baina, nahiz eta airearen osagairik ugariena izan, gasegoeran egoteak beraren aprobetxamendua galarazten zuen.

Ongarrien artean, guano izeneko substantzia izan zen ongarri eraginkor gisa erabili zen lehenengoetariko bat. Itsas hegaztien eta saguzarren gorotzez osatutakoa den guano hori, Peruko eta Txileko iparraldeko hainbat irlatan metatzen da kantitate handietan. Alexander Von Humboldt alemaniar naturalista izan ei zen ongarri mota hori ezagutarazi zuena, 1799-1804 tartean inkek eta beste kultura prehispaniko askok laborantzak hobetzeko guanoa erabiltzen zutela konturatu zenean. Aitzitik, Peruko Gobernuaren dokumentu batek dioenez, Alexander Crochet izan zen guanoaren aurkitzailea 1840an (Bello, 1980). Aipaturiko dokumentuaren arabera, Crochetek argitu zuen guanoaren konposizio kimikoa eta horretatik erauzi zuen balio handiko konposatu bat: sodio nitratoa $\left(\mathrm{NaNO}_{3}\right)$. Ondorengo urteetan guanoaren erabilera nekazaritza-ongarri gisa asko hedatu zen, eta mundu mailan eskala industrialean ustiatu zen lehenengo ongarria bilakatu zen.

Urte batzuk lehenago, 1800. urtean, «nitro» (salitre edo caliche) izena duen eta sodio eta potasio nitratoan aberatsa den nahastearen meatoki garrantzitsuak topatu ziren Txileko iparraldean (Atacamako basamortuaren barruan dauden Tarapacá eta Antofagasta eskualdeetan). Guanoarekin batera, nitroa (Txileko nitratoa) nitrato-iturri ordezkaezina bihurtu zen nekazaritzan mundu osoan zehar (1. irudia). Nitroaren gorakada izan zen, besteak beste, guanoaren gainbehera nabarmenaren arrazoietako bat, nitroaren ezaugarriak guanoarenak baino hobeak baitziren, eta mineral hori guanoa baino eskuragarriagoa eta ugariagoa baitzen. Nitroaren erreserbak ugariak baziren ere, erabat estrategikoak ziren eta garai hartan munduko baliabide preziatuenetariko bat bilakatu zen. Hori dela-eta, Peru, Bolivia eta Txile herrialdeen arteko gerra piztu zen, nitroaren gerra edo hamar zentaboko gerra izenez ezagutua (1879-1883). Gatazka horren irabazlea Txile izan zen eta, horrenbestez, Boliviak Pazifiko itsasora zeukan 250 km-ko kostaldeko lurraldea galdu zuen betirako 
(Boliviaren zoritxarrerako urte batzuk geroago munduko kobre-hobirik handiena ere aurkitu zen bertan). Peruk ere hegoaldeko lurraldea eta guanozko irlak galdu zituen (Ortega, 1984).
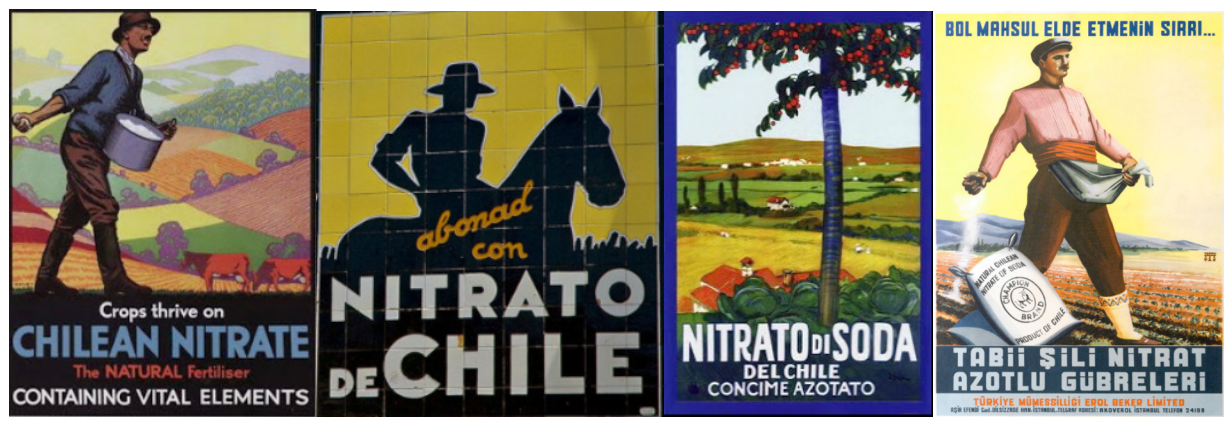

\section{1. irudia. Txileko nitratoaren iragarkiak merkatuan ongarri ospetsua eta behar-beharrezkoa zen garaian (Fernández García, 2013).}

Nekazaritzaren arrakasta guanoaren eta Txileko nitratoaren mende egon zen denbora luzez, eta mendekotasun hori arrisku estrategikoa zen herrialde askorentzat (Couyoumdjian, 1986). Hori dela-eta, XIX. mendearen bigarren erdian eta XX. mendearen hasieran ahalegin handiak egin ziren guanoaren eta Txileko nitratoaren oligopolioetatik askatuko zituen prozesu industrialen bat lortzeko. Hasierako saiakerak Frank-Caro prozesua (1895ean) eta Bikeland-Eyde prozesua (1900ean) izan ziren, besteak beste. Prozesu horiek garestiak eta antzuak ziren eta, ondorioz, erabat desegokiak ziren eskala handiko produkziorako. Helburua 1908an lortu zen, Fritz Haber kimikari alemaniarrak, $\mathrm{N}_{2}$ eta $\mathrm{H}_{2}$ gasetatik abiatuta, amoniako likidoaren lehen tantak lortu zituenean laborategi-mailan.

\section{Nitrogenoa eta haren konposatuak lehergaien garapenean}

Nitrogenoa lehergaien historiarekin erlazionaturik dago zuzen-zuzenean. Ikatz, sufre eta potasio nitratoz osaturik dagoen sutautsaren fabrikazio-prozesuarekin erlazionaturiko lehenengo idatziak XIII. mendekoak dira, Roger Bacon-en eskutik etorriak (Bacon eta Bridges, 1900). Baconek sutautsaren garrantziaz oharturik, Clemente IV.a Aita Santuari gutun baten bidez konposatu horren elaborazioa helarazi zion, etorkizuneko gatazkak irabazteko gakoa izan zitekeela adieraziz.

Nitrogenoarekin erlazionaturiko hurrengo aurkikuntza 1847an gertatu zen. Garai hartan, Ascanio Sobrero kimikari italiarrak nitroglizerina konposatua ediren zuen (nitroglizerina, trinitroglizerina edo glizerilo trinitrato izenez ere ezagutzen da gaur egun, eta $\mathrm{C}_{3} \mathrm{H}_{5} \mathrm{~N}_{3} \mathrm{O}_{9}$ formula molekularra du). Konposatu organikoa izanda, hiru osagairen nahasketaz lortzen da: azido nitrikoa, azido sulfurikoa eta glizerina (Fundación MAXAM, 2017).

Sutautsaren gaiari berriro ekinez, 1857an haren fabrikazio-prozesuak hobekuntza garrantzitsua izan zuen bai teknikoki bai ekonomikoki. Lammout Du Pont kimikari 
estatubatuarrak askoz merkeagoa zen sodio nitratoa erabili zuen potasio nitratoaren ordez. Hortik aurrera, sutautsaren formula berri horrek ohiko potasio nitratoaren bolbora beltza ordezkatu zuen (García Pacheco, 2017).

Hamar urte geroago, 1867an, Alfred Nobel izeneko kimikari suediarrak dinamita patentatu zuen. Nitroglizerina eta diatomea lurraren nahastea den lehergai berri horrek erabat ordezkatu zuen nitroglizerina, industria, meatzaritza eta armagintza esparruetan.

Datu historikoetan oinarrituta, nitrogenodun konposatuek lehergaien fabrikazioan izan duten garrantzia historian zehar zalantzagabea da, Lehen Mundu Gerran batez ere. Garai hartan Alemaniaren muga guztiak itxita zeudenez, lehergaiak fabrikatzeko Txileko nitratoaren barne-erreserbak gero eta urriagoak ziren. Baina, Fritz Haber zientzialari, militar eta abertzale alemaniarrak aireko nitrogenotik amoniakoa lortu ostean, lehergaiak fabrikatzeko prozesu industriala martxan jarri zen berehala, Haber-Bosch delako prozesua hain zuzen ere. Amoniakoaren sintesiaren lorpenari esker, Alemania lehergaiez hornitu zen (atmosferako nitrogenoa iturri amaigabea da), eta espero zitekeen baino gehiago luzatu zen historiako Lehen Mundu Gerra hura (Sieff, 2011).

Gaur egun ere, lehergai likatsu gehienek amonio nitratoa daramate euren konposizioan, nitroglizerina kantitate berdinerako eztanda-ahalmen handiagoa baitute beste oxidatzaile batzuekin alderatuta.

\section{Nitrogeno atmosferikoa finkatzea lortu zuena: Fritz Haber}

Fritz Haber, Breslau hirian jaio zen 1868an familia judu batean (garai hartan Breslau Alemaniaren barruan zegoen, baina gaur egun Wroclaw du izena eta Polonian dago). 1934an hil zen Suitzan erbesteratua 66 urterekin (2. irudia). Talentuzko zientzialaria izan zen eta bizitzaren parte handi bat zientziari (baita gerrari ere) eskaini zion. Txalotua eta saritua izan zen arren, haren lan zientifikoaren erabileragatik eta portaeragatik doilortzat hartu zuen gizarteak. Nolanahi ere, unibertsitate-irakaskuntzaren munduan haren izena aipatzea ezinbestekoa suertatzen da, zientzia eta teknologiaren arloan ekarpen itzela egin baitzuen (gaur egun ere Haber-Bosch prozesua mundu osoan zehar erabiltzen da).

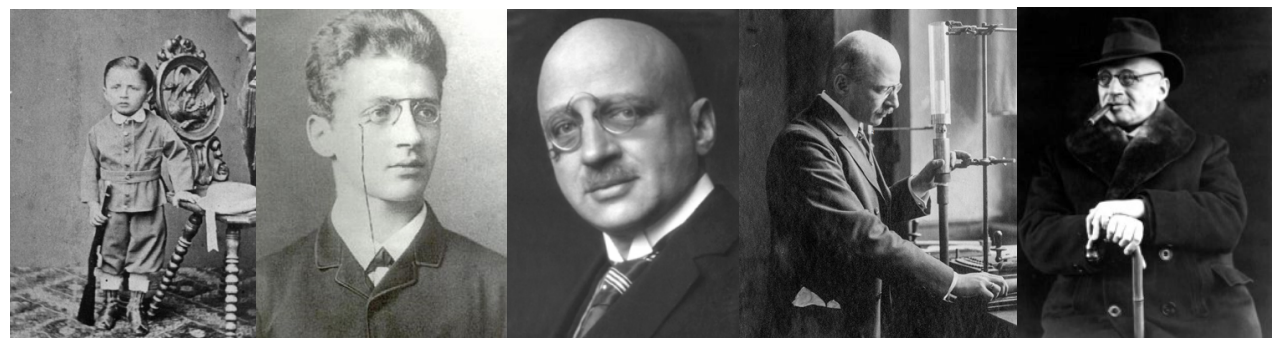

2. irudia. Fritz Haberren argazkiak haren bizitzan zehar (irudiak Berlin-Dahlem-eko Max Planck erakundearen artxibategi historikoaren eskaintza dira). 
Fritz Haber, kimikari aparta eta jenioa izateaz gain, abertzale alemaniar konbentzitua izan zen. 1914an Kaiser Wilhelm-Institut für physikalische Chemie und Elektrochemie ikerketa-institutuaren zuzendaria zela, gatazka militarretan erabiltzeko gas pozoitsuen produkziorako ikerketa-lerro berria ireki zuen. Haberren fanatismoa eta abertzaletasuna hain itsuak zirenez, bere talentua eta ospe zientifikoa erabili zituen XX. mendeko gizakiaren kontrako lehenengo sarraski handien erantzuleak ziren arma kimikoak garatzeko eta hobetzeko. Aipamen historikoen arabera, neurrigabeko nahia edukitzeaz gain, errukirik ez zeukan eta, hori dela-eta, Lehen Mundu Gerran erabili ziren arma kimiko toxikoak garatzeko ardura handia erakutsi zuen. Haren esanetan: «Bake-garaian zientzialaria munduarena da, baina gerragaraian, bere aberriarena da» (Fernández, 2015).

Frantsesak izan ziren gatazketan defentsarako arma moduan gas toxikoa erabili zuten lehenak 1914an, granada negar-eragileak erabiliz (xililo bromurozko granadak edo T-stoffak). Alemaniak ere gas negar-eragilea erabili bazuen ere, askoz eraginkorragoak ziren beste gas batzuk garatu zituen, eta gasa arma intentsibo bezala erabili zuen lehen armada izan zen.

IG Farben enpresa-konglomeratuak kloroa ekoizten zuen tinduen ekoizpenaren azpiproduktu bezala. Konglomeratua, Fritz Haberrekin elkarlanean, lubakietan kloro gaseosoa askatzeko metodo berriak garatzen hasi zen. Kloroak usain indartsua izateaz gain, hodei berdea sortzen zuen, eta, beraz, oso erraza zen hura detektatzea. Gerra-garai horretan etsaiaren kontra eraginkortasun handiagoko gasa kontzentrazio egokian zabaltzea zen erronka. Zientzialari alemaniarra izan zen gas-jaurtigailuen diseinuaren liderra. Aparailu horietan kloroa zilindro batean sartzeko diseinua asmatu zuen, gas kantitate gehiago jaurti ahal izateko, eta gasa lehergailuekin nahastu ahal izateko.

Fritz Haberrek 1918ko Nobel saria jaso zuen, amoniako-sintesiaren inguruan egin zuen ikerkuntza-lanagatik. Gerora, zientzia, etika eta politika nahastu zirenean, erabaki hori oso kritikatua izan zen, zientzialariak XX. mendeko suntsipen handiko lehen armaren garapenean izan zuen ekarpen ukaezinagatik. Gerratearen ondorioz, saria ez zen 20ko hamarkadaren erdialdera arte eman. Sari-banaketa baino hainbat hilabete lehenago, aliatuek «gerrako kriminal»en zerrenda aurkeztu zuten, eta horretan hainbat jeneralez eta komandantez gain, Fritz Haber irakasle kimikaria ere bazegoen. Garai berean, Haberrek eraginkortasun handiko pestizida bat garatu zuen, zianuroan oinarrituta hain zuzen ere. 1930eko hamarkadan naziek pestizidaren konposizioa aldatu zuten eta zyklon B delakoa sortu. Azken hori erabilita milaka pertsona erail zituzten (horietako batzuk Fritz Haberren ondorengoak) Bigarren Mundu Gerran, Auschwitz-Birkenauko, Majdaneko eta Mauthauseko kontzentrazioesparruetako gas-ganberetan.

Haberrek bere bizitza Alemania gaindiezin egingo zuten gas toxikoen garapenaren zerbitzura jarri zuen, eta momentu horretatik aurrera harreman afektibo guztiak baztertu zituen. 1901ean familia judu agurgarri baten kide zen Clara Immerwahr-ekin ezkondu zen, eta seme bat izan zuen, Hermann. Clara Breslauko Unibertsitatean zientzietan doktoratutako lehenengo emakumea izan zen, baina, Fritz Haberrekin ezkondu ostean, etxekoandre izatera eta bere senarrak antolatutako festen anfitrioi 
izatera etsi zuen. Clarak bere buruaz beste egin zuen familiaren egoitzan, bere senar tiranoak gerran gas pozoitsuen sintesian eta erabileran izan zuen protagonismoaren kontra zegoelako erabat. Haber berriro ezkondu zen, baina dibortziatu egin zen eta haren bigarren emaztea, Charlote Nathan, eta haren bi semeak Ingalaterrara joan ziren bizitzera.

Hitler-ek boterea hartu zuenean 1933an, Haberren esfortzu aberkoiak, kontribuzio zientifikoa edo Nobel saria ez ziren nahikoa izan naziei haren jatorri judua ahatzarazteko. Ondorioz, Alemaniatik ihes egin behar izan zuen. Hermann, lehenengo semea, Estatu Batuetara joan zen Bigarren Mundu Gerra bukatu baino lehenago, eta amak bezala, bere buruaz beste egin zuen 1946an. Bigarren emaztearekin eduki zituen bi semeetariko bat, Ludwig Fritz Haber (1921-2004), Lehen Mundu Gerran erabilitako arma kimikoei buruzko goi-mailako historialari bihurtu zen, eta Hodei pozoitsua (1986) izendaturiko liburua argitaratu zuen (Haber, 1986). Liburuan bildutako informazioari esker, Fritz Haberren izaerari eta bizitzari buruzko datu fidagarriagoak dauzkagu gaur egun. Haren semearen hitzetan, «antolatzaile izugarri sutsua, ausarta eta, segur aski, kontzientziagabea» izan zen.

\section{Ondorioak eta eztabaidak}

Historian zeharreko zenbait kasutan gizakiaren beharrak asetzeko naturaren ezintasuna larria izan denean, irtenbideak aurkitu dira aurkikuntza zientifikoak eta teknologikoak bat eginez; adibide askoren artean esanguratsuenetariko bat dugu aurreko atalean aurkeztu den Fritz Haber zientzialari alemaniarrak lorturiko amoniakoren sintesiaren prozesua. Hala ere, irtenbide horien ingurumen-kostua ez da kontuan hartu izan, gizartean arazo larriak sortu arte.

Azken urteotan garapen zientifiko eta teknologikoak eragindako inpaktu ekologikoak piztu duen arreta geroz eta handiagoa da, bai mundu akademikoan, bai arduradun politikoen artean eta gizartean ere. Hazkunde ekonomikoaren eta aurrerapen eta garapen teknologikoaren arteko erlazio estua aspaldi onartu den arren, ondorio kaltegarriak ezin dira alde batera utzi. Izan ere, baliabide naturalen erabilera berekoiaren aurkako ahotsak biziagotu egin dira azken hamarkadetan, garapen iraunkorraren aldeko jarrerak indartuz. Kasurik onenean eta baikorrak izan nahian, nazioarteko akordio politiko zorrotzak lortzea eta errespetatzea oso zaila dela erakutsi dute Kyotoko protokoloak, Kopenhageko konferentziak eta Pariseko akordioak (García Lupiola, 2017).

Nitrogenoa duten konposatuak eguneroko bizitzan agertzen zaizkigu, adibidez, goritasun-lanparetan, elikagaietan, medikamentuetan, beste askoren artean. Amoniakoa, adibidez, behar-beharrezkoa da hainbat produktu komertzial fabrikatzeko (3. irudia) eta oraindik ere lehengai gisa erabiltzen da laborantza intentsiboa segurtatzen duten nitrogenodun ongarriak fabrikatzeko. Izan ere, Haber-Bosch prozesu industrialaren bitartez ekoitziriko nitrogenoaren \% 80 laborantza-ongarrien merkatuan saltzen da lehengai gisa, nahiz eta amoniako horren $\% 17$ besterik ez duen gizakiak kontsumitzen elikagai gisa. Zoritxarrez, ongarri nitrogenodun horien erabilera intentsiboak ingurumenaren osasuna erabat kaltetu du, baina ondorio 
kaltegarri horiei buruz oso gutxi entzuten da komunikazio-baliabideetan. Adibidez, gaur egun bioerregaiak erabiltzea irtenbide ekologikoa eta iraunkorra dela esaten da erregai fosilak ordezkatzeko. Bioerregaiak ongarrien bidez hazitako landareetatik erauzten dira, eta, esate baterako, bioetanol galoi bat ekoizteko artoa hazten sorrarazten den berotegi-efektua askoz larriagoa da gasolinarena baino (Howarth et al., 2009). Kutsadura hori lurzoruan edo atmosferan pilatzen da, ur-ekosistemen eutrofizazioa sortuz eta atmosferaren balantzea desorekatuz. Habitat-eraldaketa eta klima-aldaketaren ostean, lurreko bioaniztasuna mehatxatzen duen hirugarren faktorerik garrantzitsuena da nitrogenoaren ziklo naturalaren aldaketa (Sala et al., 2000).

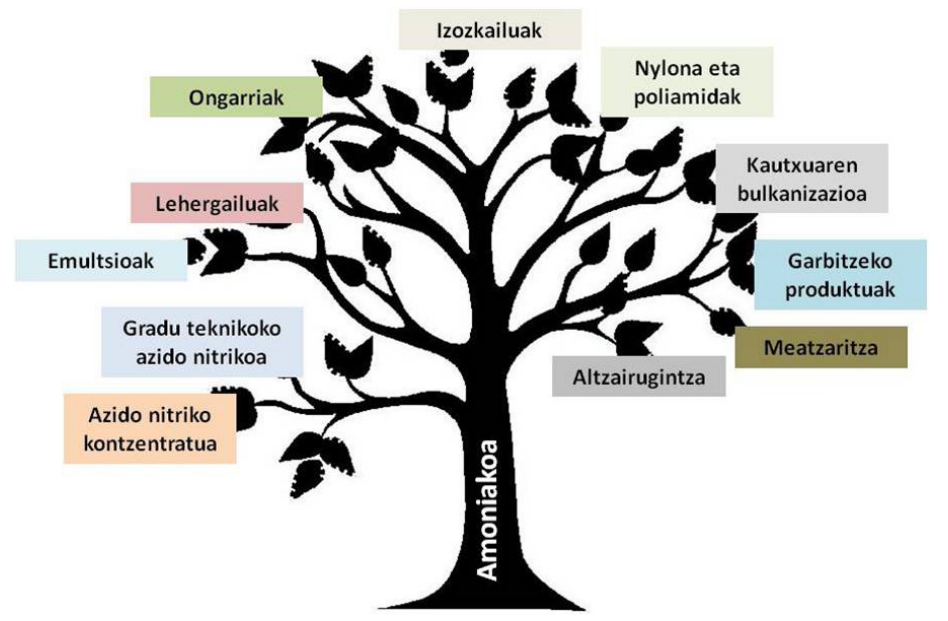

3. irudia. Amoniakoa lehengai gisa erabiltzen den hainbat produktu eta erabilera.

Industriaurreko garaiarekin alderatuz, atmosferara isurtzen den egungo nitrogeno monoxido eta amoniakoaren emisio-tasak bikoiztu egin dira. Giza eraginik ezean, atmosferan dagoen nitrogenoaren deposizio-maila urteko $0,5 \mathrm{~kg} \mathrm{~N}^{-1}$ edo txikiagoa izan arren, Lurreko eskualde zabal askotan neurtu diren batez besteko balioak $10 \mathrm{~kg}$ $\mathrm{N} \mathrm{ha}^{-1}$ urte $^{-1}$-tik gorakoak dira (Erisman et al., 2008).

Hala eta guztiz ere, Lurraren berotze-efektuarekin alderatuta, nitrogenoaren kutsadura ez da oso ezaguna gizartean, konponbide-ekintza premiazkoak behar dituen arazo larrienetariko bat bada ere. Aipaturiko ezjakintasunaz gain, eskuragarri dagoen informazio zientifiko urriak ez ezik, nitrogenoaren inguruan dauden kontraesanek ere badute horren zergatia. Kutsadura larria sortu arren, Razon ikertzaileak egin zuen galderaren erantzuna («Is nitrogen fixation (once again) "vital to the progress of civilized humanity"?») baiezkoa da XXI. mendean (Razon, 2015).

Arazoa larriagoa izan ez dadin, hainbat proposamen egin dira:

1. Ongarri organikoak erabiltzea eta nekazaritza-laborantza hobetzea. Nekazaritza organikoan nitrogenoaren lixibiazioa, $\mathrm{N}_{2} \mathrm{O}$ igorpenak eta amoniakoaren kontsumoa txikiagoa da laboraturiko gainazala kontuan hartuta, baina ekoitziriko produktu kantitatea kontuan hartuta handiagoa da (Tuomiso et al, 2012; Razon, 2015). 
2. Gizartearen populazioaren hazkuntza kontrolatzea. 1908an landaturiko hektarea bakoitzeko 1,9 gizaki mantentzen ziren eta 2008an 4,3 gizaki (Smil, 2011).

3. Gizarte aurreratuetan okela eta esne-produktu gutxiago kontsumitzea. Europan eta Ipar Ameriketan okela eta esne-produktu gehiegi kontsumitzen dira eta horrek ongarrien premia handia dakar. Tamalez, ohitura hori aldatzea ia-ia ezinezkoa da, nahiz eta dieta hori oso osasungarria ez izan (Erisman et al., 2008).

4. Genetikoki aldaturiko zerealak eta elikagai gisa erabiltzen diren landare batzuk lantzea. Era horretan, nitrogenoa era naturalean finka daiteke lurzoruan, baina elikagai horiek ez dira ongi onartzen kontsumitzaileen artean (Oldroyd eta Dixon, 2014; Delaux, Radhakrishnan eta Oldroyd, 2015).

5. Ur-araztegietan eta beste tratamendu batzuetan nitrifikazio-desnitrifikazio prozesuak indartzea eta sorturiko $\mathrm{N}_{2}$-a berrerabiltzea. Disolbaturik dauden nitrogeno-konposatuek $\mathrm{N}_{2}$ gasa ekoitzi dezakete bakteriak erabiliz. $\mathrm{N}_{2}$ hori guztia batu eta berrerabiltzeko proposamena egin da, baina edozein kasutan, ez da nahikoa eskaera betetzeko gaur egun.

Bukatzeko, artikulu honetan erakutsi da gaur egun Haber-Bosch prozesua aldi berean ordezkaezina eta jasanezina dela. Denboran zehar amoniakoaren sintesiak eragin dituen kalteak azpimarratu dira, nahiz eta garai batean elikagaien gabeziaren irtenbidea izan zen. Urte askotan berrikuntza hori txalokatua izan da, baina tamalez, ehun urte geroago konponbide zalantzagarria duen ingurumen-arazo larria ere sortu duela erakutsi da artikulu honetan. Nitrogenoa finkatzeko prozesu iraunkorra aurkitzea premiazkoa den arren, jadanik finkaturik dagoen nitrogenoa era iraunkorragoan erabiltzen ikasi behar dugu, gure etorkizunaren giltza baita.

\section{Esker onak}

Egileek esker onak eman nahi dizkiote Euskal Herriko Unibertsitateari GIU15/20 proiektuaren barruan izan duten diru-laguntzagatik.

\section{Erreferentzia bibliografikoak}

Bacon, R. eta Bridges, J.H. (1900): The «Opus majus» of Roger Bacon, Williams \& Norgate, Northwestern University, Chicago.

Barona, A. et al. (2017): «A Unique Historical Case to Understand the Present Sustainable Development», Science and Engineering Ethics Journal, 24, 261-274.

Bello, A. (1980): Informes inéditos de diplomáticos extranjeros durante la guerra del Pacífico, Andrés Bello, Santiago (Txile).

Couyoumdjian, J.R. (1986): Chile y Gran Bretaña durante la primera Guerra Mundial y la postguerra, Andrés Bello, Santiago (Txile).

Delaux, P.M.; Radhakrishnan, G. eta Oldroyd, G. (2015): «Tracing the evolutionary path to nitrogen-fixing crops», Current Opinion in Plant Biology, 26, 95-99.

Erisman, J.W. et al. (2008): «How a century of ammonia synthesis changed the world», Nature Geoscience, 1, 636-639. 
Fernández, L. (2015): Fritz Haber: vida y muerte a través de la química, <https://www. detectivesdelahistoria/fritz-haber-vida-y-muerte-a-traves-de-la-quimica/> (Kontsulta: 2018-01-12).

Fernández García, A. (2013): El guano y el salitre, dos recursos naturales que hicieron historia, <http://chajurdo.blogspot.com.es/2013/04/el-guano-y-el-salitre-dosrecursos.html> (Kontsulta: 2018-01-22).

Fundación MAXAM (2017): Alfred Nobel: de la nitroglicerina a la dinamita, <https://www. maxam.net/es/fundacion/casa_explosivo/alfred_nobel_nitroglicerina> (Kontsulta: 2017-05-03).

García Lupiola, A. (2017): «Klimari buruzko negoziazioak, Kyotoko Protokoloa ordezkatuko duen akordio baterako: Kopenhageko porrotetik Parisko Akordiora», Uztaro, 103, 5-25.

García Pacheco, C. (2017): Sistemas de explosivos, UTEM, Universidad Tecnológica Metropolitana, Santiago (Txile).

Haber, L.F. (1986): The poisonous cloud, Clarendon Press, Oxford.

Hager, T. (2008): The Alchemy of Air, Broadway books, New York.

Howarth, R.W. et al. (2009): «Rapid assessment on biofuels and the environment: Overview and key findings", Proceedings of the Scientific Committee on Problems of the Environment (SCOPE). International Biofuels Project Rapid Assessment, 2008ko irailaren 22-25a, Gummersbach, Alemania.

Malthus, T.R. eta Keynes, J.M. (2016): Primer Ensayo sobre la Población, Alianza Editorial, Madril.

Oldroyd, G.E.D. eta Dixon, R. (2014): «Biotechnological solutions to the nitrogen problem», Current Opinion in Biotechnology, 26, 19-24.

Ortega, L. (1984): Los empresarios, la política y los orígenes de la Guerra del Pacífico, FLACSO, Santiago (Txile).

Razon, L.F. (2015): «Is nitrogen fixation (once again) "vital to the progress of civilized humanity"?», Clean Technologies and Environmental Policy, 17(2), 301-307.

Sala, E. et al. (2000): «Global Biodiversity Scenarios for the Year 2100», Science, 287, 17701774.

Sieff, M. (2011): Seven Billion Humans: The World Fritz Haber Made, <https:/www.theglobalist. com/seven-billion-humans-the-world-fritz-haber-made> (Kontsulta: 2017-03-05).

Smil, V. (2011): «Nitrogen cycle and world food production», World Agriculture, 2, 9-13.

Tuomiso, H.L. et al. (2012): «Does organic farming reduce environmental impacts? A metaanalysis of European research», Journal of Environmental Management, 112, 309-320. 

